\section{Colorimetric Detection of the Tuberculosis Complex Using Cycling Probe Technology and Hybridization in Microplates}

BioTechniques 28:1152-1160 (June 2000)

\begin{abstract}
Cycling probe technology (CPT) is a simple signal amplification method for the detection of specific target DNA sequences. CPT uses a chimeric DNA-RNA-DNA probe that is cut by RNase $H$ when bound to its complementary target sequence. In this study, a hybridization assay was developed to detect biotinylated CPT products that result from the amplification of a Mycobacterium tuberculosis complex sequence. The chimeric probe was specifically designed to avoid the formation of secondary structures. The chosen capture probe was perfectly complementary to and was the same size as OL2, one of the two CPT products. The assay was based on the observation that a long sequence, such as the initial probe, was destabilized when bound to a small capture probe as a result of steric hindrance. The capture probe preferentially bound OL2 rather than the long initial probe. We added a prehybridization step with a helper DNA to enhance this discrimination between the two sequences. Colorimetric detection was performed using a peroxidase-streptavidin conjugate. After optimization, the non-isotopic hybridization assay allowed the detection of around 10 amol of target DNA. Besides being faster and easier to perform, this detection method was compared to electrophoresis separation and gave similar results.
\end{abstract}

\section{INTRODUCTION}

Cycling probe technology (CPT) is an isothermal signal amplification method for the detection of specific target DNA sequences (Figure 1). A chimeric probe, DNA-RNA-DNA and thermostable RNase $\mathrm{H}$ are the two main components of this assay. In the presence of the target sequence, a DNA/RNA hybrid is formed and RNase $\mathrm{H}$ specifically catalyzes the cleavage of the RNA portion of the hybrid. Since cleaved fragments are small, they dissociate spontaneously from the target sequence at the reaction temperature. The target is then recycled and available for hybridization with another probe; the reaction is inherently cyclic without external manipulations $(8,19)$. The labeled, cleaved probes accumulate with time and are detected as described here. Since there is no target amplification, carryover contaminations are minimized (1).

Usually, the chimeric probe is labeled with radioisotope $\left[\gamma^{-32} \mathrm{P}\right]$, and the cleaved probe percentage is evaluated by electrophoresis on a polyacrylamide gel $(1,7,9,12,13)$. This method is time consuming, limits the number of samples that can be simultaneously analyzed and is not easily automated. Furthermore, the use of radioisotopes such as $[32 \mathrm{P}]$ is not optimal because of safety reasons (6) and for their short half-life that requires frequent probe preparation (16). Nonradioisotopic detection has already been developed for the detection of the mecA gene (2), but it was a subtractive assay that was limited to a dynamic range of less than one order of magnitude.

The purpose of this study was to develop a nonradioactive detection method by hybridizing the cleaved probes on capture probes covalently bound on a microplate $(21,22)$. The challenge was to specifically detect the cleaved probe while the initial uncut probe was still present in solution. The steric hindrance of the support should favor the hybridization of the cut probe. Moreover, a prehybridization step was added in the presence of a helper probe to further prevent the hybridization of the uncut probe on the capture probe (Figure 1). The biotinylated probes were then detected by colorimetry through a streptavidin-peroxydase complex.

The method was developed for the detection of the tuberculosis complex. In fact, the presence of bacteria from this complex (Mycobacterium tuberculosis, M. bovis, M. bovis BCG, M. microti and $M$. africanum) requires a rapid and sensitive diagnosis that cannot be provided by classical microbiological methods that rely on morpho- logical, biochemical and growth properties $(8,17,18)$. A fast diagnosis is one of the requirements for the effective control of tuberculosis (20).

\section{MATERIALS AND METHODS}

\section{Radioisotopic Labeling of Probes}

The probes were labeled with ATP [ $\left.\gamma^{-32} \mathrm{P}\right]$ (Dupont Denemours, Brussels, Belgium) by incubation with T4 polynucleotide kinase (Roche Molecular Biochemicals, Mannheim, Germany) for $30 \mathrm{~min}$ at $37^{\circ} \mathrm{C}(3)$. The addition of $0.25 \mathrm{M}$ EDTA stopped the reaction. Labeled probes were purified on a G25 Sephadex ${ }^{\circledR}$ column (Roche Molecular Biochemicals, Mannheim, Germany).

\section{Covalent DNA Immobilization in Microwells}

The capture DNA probe was covalently attached to the microwells by the formation of a phosphoramidite bond between the $5^{\prime}$ terminal phosphate group and the aminogroup of the polystyrene microwells $(15,21,22)$.

The capture probe ( $25 \mathrm{pmol})\left(5^{\prime}\right.$ TCGGCACGGACACGGCTCTGACAT-3') (Eurogentec, Seraing, Belgium) was heated for $10 \mathrm{~min}$ at $94^{\circ} \mathrm{C}$ and mixed with $10 \mathrm{mM} 1$-methylimidazole ( $\mathrm{pH}$ 7.5). The solution was then dispensed into the microwells (75 $\mu \mathrm{L} /$ well) (Covalink-NH; Nalge Nunc, Roskilde, Denmark). Forty micromoles of EDC [1-ethyl-3(3-dimethylaminopropyl)-carbodiimide] (Sigma, St. Louis, MO, USA) were dissolved in 10 $\mathrm{mM}$ 1-methylimidazole and $25 \mu \mathrm{L}$ were added to each well. The plates were incubated at $50^{\circ} \mathrm{C}$ for $5 \mathrm{~h}$ and subsequently washed three times for $5 \mathrm{~min}$ with $0.4 \mathrm{M} \mathrm{NaOH} / 0.25 \%$ Tween ${ }^{\circledR} 20$. After a last wash with water, the plates were dried and kept at $4^{\circ} \mathrm{C}$.

\section{CPT Assay}

The chimeric probe was chosen within the mycobacterial fragment Mt308; this sequence is specifically present in mycobacteria belonging to the tuberculosis complex and found as a single copy in the genome $(18,19)$.

Two secondary-structure prediction 
Table 1. Comparison of Three CPT Detection Methods

\begin{tabular}{|c|c|c|c|}
\hline & \multicolumn{2}{|c|}{ Radioisotopic } & \multirow{2}{*}{$\begin{array}{l}\text { Colorimetric } \\
\text { Hybridization }\end{array}$} \\
\hline & Polyacrylamide gel & Hybridization & \\
\hline Probe amount used & 2 fmol OLM1 & 100 fmol OLM1 & $100 \mathrm{fmol}$ OLM1b \\
\hline Detection limit & $1-10 \mathrm{amol}$ & $10-100 \mathrm{amol}$ & 10 amol \\
\hline $\mathrm{C} 1 / \mathrm{C} 2$ & $1 / 5$ & $1 / 2$ & $1 / 2$ \\
\hline $10^{-17 / C 2}$ & 3.8 & 1.6 & 1.9 \\
\hline \multicolumn{4}{|c|}{$\begin{array}{l}\text { Two methods were radioisotopic (electrophoresis and hybridization) and used the probe OLM1. The third method was } \\
\text { colorimetric hybridization and used the biotinylated probe OLM1b. We compared the amount of probe used as substrate, the } \\
\text { detection limit, the ratio between the controls }(\mathrm{C} 1 / \mathrm{C} 2) \text { and the ratio between the signals obtained with a target concentration } \\
\text { of } 10 \text { amol and the control } \mathrm{C} 2 \text {. }\end{array}$} \\
\hline
\end{tabular}

programs were used to design the chimeric probes. The first was Oligo 6, which predicts the stability of probes and displays hairpins of more than $3 \mathrm{bp}$ (5). The second, DNA fold, was developed by M. Zucker (10) for RNA and adapted to DNA by Nielsen (14). It is based on free-energy minimization and predicts the most stable secondary structures present at different temperatures. Naview, the program discussed by Bruccoleri and Heinrich (23), al-

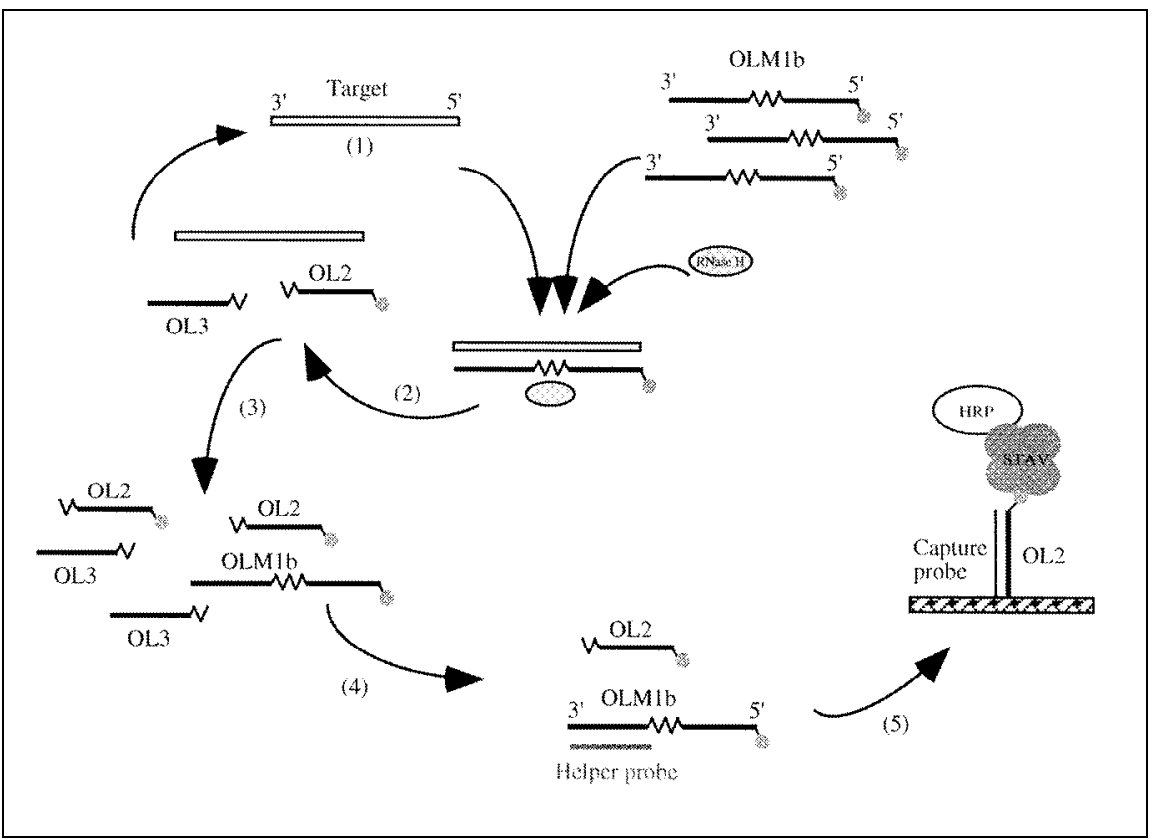

Figure 1. Diagram of CPT colorimetric detection assay used for the detection of target DNA. Singlestranded target DNA was used as the template. (1) In the presence of probe OLM1b and RNase H, the RNA portion of the probe-target complex was cleaved by RNase $\mathrm{H}(2)$. The cleaved probe fragments dissociated from the target, thereby regenerating the target, DNA for further cycling (3). After amplification, a DNA helper probe was added to the solution to prevent the hybridization of OL3 and OLM1b with the capture probe (4). The solution was then incubated in a multiwell plate bearing a capture probe complementary to the OL2 fragment (5) and biotin is detected in colorimetry using a streptavidin peroxidase conjugate. quence was 5'-ACTCGGGGTAACACTTCGGCACGGACACGGCTCTGACAT-3' (Eurogentec).

The reaction mixture $(10 \mu \mathrm{L}$ final $)$ contained cycling buffer $[50 \mathrm{mM}$ Tris$\mathrm{HCl}(\mathrm{pH} 8.1), 8 \mathrm{mM} \mathrm{MgCl}_{2}$ and $0.025 \%$ Triton $\left.{ }^{\circledR} \mathrm{X}-100\right], 100$ fmol chimeric probe, 5.7 pmol RNase H (ID Biomedical) and different amounts of target sequence. The mixture was incubated for $30 \mathrm{~min}$ at $70^{\circ} \mathrm{C}$.

In each experiment, two reaction controls, $\mathrm{C} 1$ and $\mathrm{C} 2$, were carried out without target sequence, where $\mathrm{C} 1 \mathrm{did}$ not contain RNase $\mathrm{H}$ and $\mathrm{C} 2$ did. $\mathrm{C} 2$ was essential to evaluate the nonspecific degradation of the chimeric probe. The CPT reaction was stopped by adding $5 \mu \mathrm{L}$ loading buffer ( $8 \mathrm{M}$ urea, $0.1 \mathrm{M}$ EDTA, $0.25 \%$ bromophenol blue and $0.25 \%$ xylene cyanol).

\section{Amplification Product Analysis on a Polyacrylamide Gel}

The CPT products were separated by electrophoresis on a $20 \%$ polyacrylamide gel in denaturing conditions (7 $\mathrm{M}$ urea) at $200 \mathrm{~V}$ for $3 \mathrm{~h}$. The amount of the respective products was estimated by integration of the different bands (intact and digested probe) with an Instant Imager (Packard, Downers Grove, IL, USA).

\section{Amplification Product Analysis by Hybridization}

For the prehybridization step, the CPT reaction was stopped by heat denaturation at $94^{\circ} \mathrm{C}$ for $10 \mathrm{~min}$. Then, 10 
pmol in $10 \mu \mathrm{L}$ helper DNA (5'-ACTCGGGGTAACACTTCGGCACGGA$\left.3^{\prime}\right)$ (Eurogentec) and $50 \mu \mathrm{L}$ hybridization buffer $(0.5 \times \mathrm{SSC}$ and $100 \mu \mathrm{g} / \mathrm{L}$ ssDNA), both purchased from Sigma, were added and incubated for $1 \mathrm{~h}$ at $45^{\circ} \mathrm{C}$ in microtubes.

For the hybridization step, the wells bearing the DNA capture probe were incubated with $0.2 \mathrm{M} \mathrm{NaOH}$ for $5 \mathrm{~min}$ and then washed with $0.2 \times$ SSC. The prehybridization mixture was transferred to the wells and incubated for $2 \mathrm{~h}$ at $50^{\circ} \mathrm{C}$. The wells were then washed three times for $5 \mathrm{~min}$ with $0.4 \times \mathrm{SSC}$ warmed to $45^{\circ} \mathrm{C}$. For detection when using the radioisotopic probe, the wells were removed and radioactivity was counted in a scintillation counter (Beckman Coulter, Fullerton, CA, USA). When colorimetric detection was used, wells were washed once with blocking buffer to decrease the background by saturating the surface with proteins $[0.1 \%$ Gloria milk powder in buffer 1:0.1 M maleic acid, $0.15 \mathrm{M} \mathrm{NaCl}(\mathrm{pH}$ 7.5)], and $100 \mu \mathrm{L}$ streptavidin-peroxidase conjugate (Medgenix, Fleurus, Belgium) diluted $1000 \times$ in blocking buffer was dispensed into wells. After a 45-min incubation at room temperature, the wells were washed three times for 5 min with buffer 2 (buffer 1 plus $0.3 \%$ Tween 20) and once for 5 min with buffer 1 . The substrate tetramethyl benzidine (TMB) (Medgenix) was added $(100 \mu \mathrm{L} /$ well $)$ and incubated for $15 \mathrm{~min}$ in the dark. The addition of $100 \mu \mathrm{L}$ acidic solution (Medgenix) stopped the colorimetric reaction. The absorbance was then measured at $405 \mathrm{~nm}$. The values were corrected for the background of the plastic by measuring this absorption at $655 \mathrm{~nm}$.

\section{RESULTS AND DISCUSSION}

\section{Chimeric Probe Design}

The chimeric probe OLM1 was selected within the Mt308 sequence and consisted of 33 matching bases flanked by six nonspecific bases at the $5^{\prime}$ end. This six-base-stretch was part of the fragment hybridizated on the capture probe. The presence of secondary structure in OLM1 was checked using Oligo 6 and DNA fold prediction programs.

In our first attempt, we observed high $\mathrm{C} 2$ values from the spontaneous cleavage of the probe in the presence of RNase H (data not shown). This cleavage was the result of secondary structures within the probe. To eliminate this nonspecific cleavage, the number of RNA bases within the chimeric probe was reduced from four to three bases.
The use of three RNA bases is known to slightly reduce the efficiency of the CPT (11); in our case, it was necessary to decrease the cleavage of the initial probe. Following the action of RNase $\mathrm{H}$, OLM1 was cleaved into two small probes: OL2 on the $5^{\prime}$ side and OL 3 on the $3^{\prime}$ side of the initial probe. After amplification, the OL2 fragment was the only one labeled.

\section{Detection by Hybridization on a Microplate}

A unique feature of this work was investigating the possibility of discriminating between OL2 and OLM1 by hybridization on a capture probe linked at the bottom of the well. Theoretically, the two probes could hybridize because they are both complementary to the capture probe. However, OLM1 is longer than OL2, and when fixed on the capture probe, a steric hindrance will create an instability. We decided to use this physical hindrance to discriminate between the OL2 and OLM1 sequences for this hybridization step.

\section{Capture Probe Immobilization on Microwells}

The capture probe immobilization was a crucial step in influencing the sig-

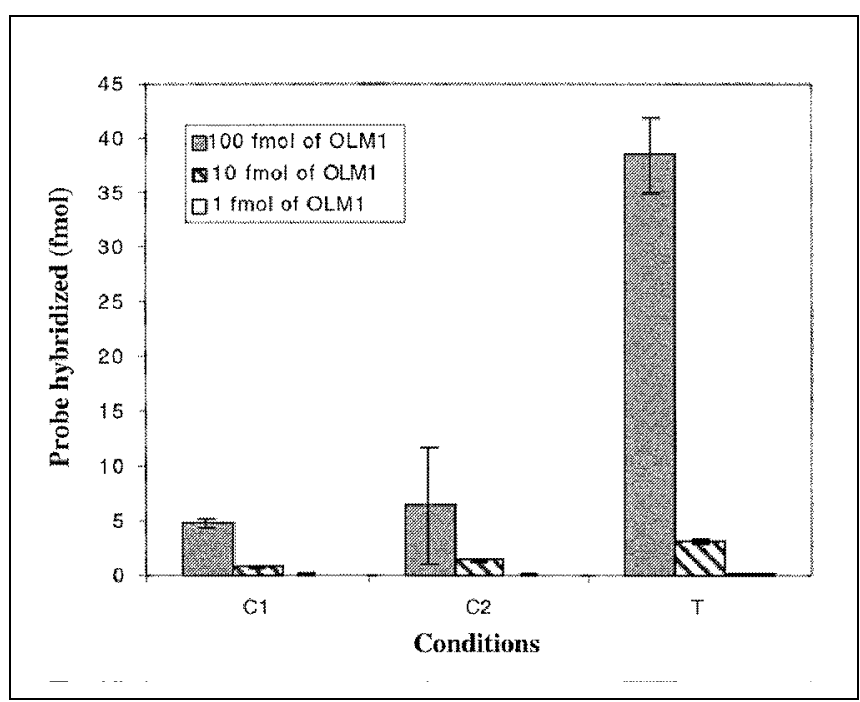

Figure 2. Titration of the amount of OLM1 probe in the CPT hybridization assay. The amount of DNA target $(\mathrm{T})$ was $1 \mathrm{fmol}$. Prehybridization was performed with 10 pmol helper DNA. Two controls were added: $\mathrm{C} 1$ included the probes but no target and no RNase $\mathrm{H} ; \mathrm{C} 2$ included the probe and $\mathrm{RNase} \mathrm{H}$ but no target. Results were expressed as the amount of CPT products hybridized to the capture probe.

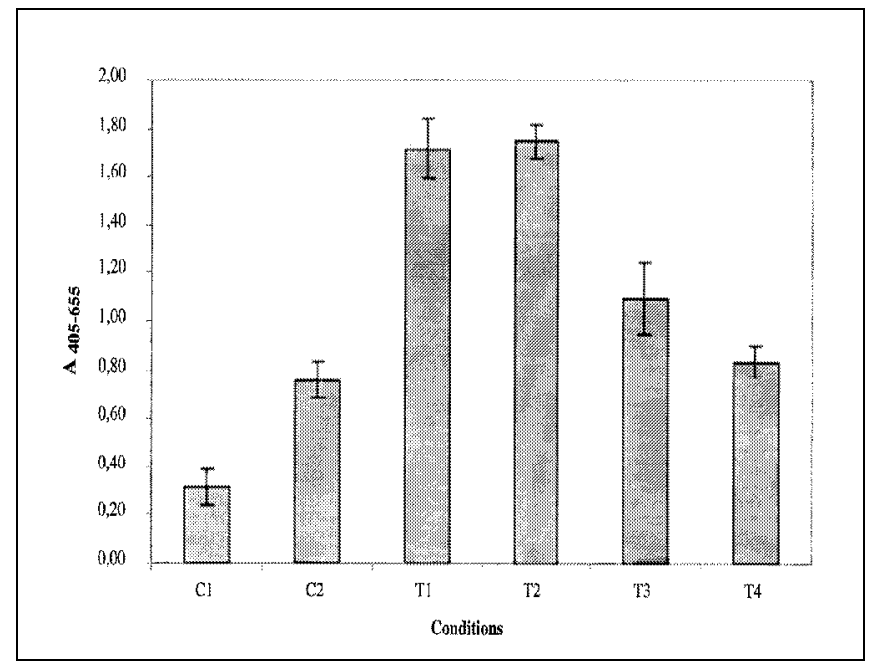

Figure 3. Histogram showing the detection limit obtained by CPT amplification and colorimetric detection. CPT was performed with $100 \mathrm{fmol}$ OLM1b. Targets were serially diluted as follows: 1 fmol (T1), 100 amol (T2), $10 \mathrm{amol}$ (T3) and $1 \mathrm{amol}$ (T4). The prehybridization step was performed with 10 pmol helper DNA. Two controls were added: $\mathrm{C} 1$ included the probes but no target and no RNase $\mathrm{H} ; \mathrm{C} 2$ included the probe and RNase $\mathrm{H}$ but no target. Results were expressed as the OD at $405-655 \mathrm{~nm}$. 
nal-to-noise ratio and affecting the sensitivity of the assay $(4,6)$. Covalent binding of DNA on microwells was obtained by fixation on the $5^{\prime}$-end-activated amino group on the plastic $(15,22)$. Variable amounts (10, 25 and $50 \mathrm{pmol})$ of $5^{\prime}$ end-radiolabeled capture probes were fixed to define the amount that gives the best fixation yield. This immobilization reaction was performed for $5 \mathrm{~h}$ at $50^{\circ} \mathrm{C}$ in $10 \mathrm{mM}$ methylimidazole buffer $(\mathrm{pH}$ 7.5) with $40 \mathrm{mM}$ EDC. Nonspecific fixation was estimated by carrying out the reaction in the absence of EDC.

The amount of bound capture probe increased with the starting amount up to a maximum level when 25 pmol was added (data not shown). Under these conditions, 0.5 pmol capture probe was fixed on the solid support, and the nonspecific binding was quite low. Therefore, 25 pmol capture probe was selected to carry out the fixation process on the microplates.

\section{OL2 Detection by Hybridization on the Microplate}

During the CPT assay, the OLM1 probe is cleaved into two small fragments, OL2 and OL3. OL2 is labeled and detected after hybridization on the capture probe fixed in the wells. Hybridization conditions were first optimized using purified radiolabeled OL2. Different times and temperatures were tested. Since the principle of this differential assay is based on the destabilization of the OLM1 hybridization by steric hindrance, the study of the temperature and the stringency of the washing conditions was a crucial step. The most effective washing condition was three times with $0.4 \times \mathrm{SSC}$ at $45^{\circ} \mathrm{C}$ for 5 min (data not shown). Under these conditions, we obtained a good yield for the hybridization of the OL2 sequence with a minimal amount for OLM1. However, the discrimination was not absolute.

We decided to perform a prehybridization step in the presence of a small blocking sequence (helper DNA). The optimal conditions used to block OLM1 binding were 10 pmol helper DNA incubated for $1 \mathrm{~h}$ at $45^{\circ} \mathrm{C}$. The helper probe sequence hybridized to a part of the OLM1 RNA sequence, but RNase $\mathrm{H}$ was inactivated at that time, so there was no cleavage.
Finally, the CPT conditions were adapted to the detection of OL2 by hybridization. We found that increasing the OLM1 amount to $100 \mathrm{fmol}$ led to an increase in OL2 detection (Figure 2 ). Once hybridization conditions were optimized with OLM1, we performed the CPT with the biotinylated probe OLM1b and compared the sensitivity of this hybridization assay with classical radioisotopic detection by electrophoresis on a polyacrylamide gel.

\section{Detection Limit of the CPT Assay}

A colorimetric hybridization assay was performed on the CPT products (Figure 3), and results were compared to those obtained after radioisotopic hybridization assay or electrophoretic analysis of the CPT products (Table 1). Different parameters such as the detection limit and the $\mathrm{C} 1: \mathrm{C} 2$ ratio were compared.

In the colorimetric detection after hybridization, a high signal was obtained for a target concentration of 1 fmol and 100 amol (Figure 3). The signal then decreased and reached, at 1 amol, a value close to the $\mathrm{C} 2$ control. The $\mathrm{C} 1$ value represented the detection of the OLM1b substrate probe alone, while the $\mathrm{C} 2$ value also took into account the nonspecific cleavage of the probe by RNase $\mathrm{H}$. We could conclude that, for this assay, the detection limit was around 10 amol of target DNA (107 target copies), which corresponded to the limit obtained for mecA gene detection (7). The dynamic range of this assay reached nearly two logs, which is higher than the nonradioisotopic system described elsewhere (7).

The lower sensitivity in hybridization was partially a result of higher signals obtained in the controls. On a polyacrylamide gel, the cleaved probe migrated faster and could be quantified without interference from the starting probe. However, when detected by hybridization, there is little binding of OLM1, even in the optimized conditions. This effect can be observed by a higher $\mathrm{C} 1$ value and a decrease in the $\mathrm{C} 1: \mathrm{C} 2$ ratio (Table 1$)$. When added at the same concentration, the ratio between the hybridization of OLM1b and OL2 was 11.7. This means that out of the 100 hybridized probes, nine were 
OLM1b. This OLM1b binding increased both $\mathrm{C} 1$ and $\mathrm{C} 2$ values because a 50-fold higher amount of OLM1b was used in this assay compared with the electrophoretic separation assay

Compared to electrophoretic separation, the differential hybridization proposed here is slightly less sensitive, quite simple to perform and can be part of an automation process with a robot adapted for 96 wells. The future development of the colorimetric detection of CPT products in microwells by the method described above involves its application in diagnostics. However, some problems could occur if one wants to apply CPT to clinical samples because they may contain nonspecific RNases. Moreover the high amounts of human genomic DNA affect the yield of the probe's cleavage. It has been shown by Modrusan et al. (12) that the presence of genomic DNA in CPT resulted in high background and was inhibitory. Addition of spermidine and EGTA into the CPT reaction greatly improved the assay (12).

The CPT assay is rapid and does not require an expensive instrument. Once its adaptation to clinical samples is made possible, it may provide a real alternative to the PCR-based assays in molecular microbiology.

\section{REFERENCES}

1.Beggs, M., M. Cave, C. Marlowe, L. Cloney, P. Duck and K. Eisenach. 1996. Characterization of mycobacterium tuberculosis complex direct repeat sequence for use in cycling probe reaction. J. Clin. Microbiol. 34:29852989.

2.Bekkaoui, F., J. McNevin, C.H. Leung, G. J. Peterson, A. Patel, R.S. Bhatt and R.N. Bryan. 1999. Rapid detection of the mec A gene in methicillin resistant staphylococci using a colorimetric cycling probe technology. Diagn. Microbiol. Infect. Dis. 34:83-90.

3.Berkner, K. and W. Folk. 1977. EcoRI cleavage and methylation of DNAs containing modified pyrimidines in the recognition sequence. J. Biol. Chem. 252:3185-3193.

4.Bernt, C., M. Bebenroth, K. Oehlschlegel, F. Hiepe and W. Schöbler. 1995. Quantitative polymerase chain reaction using a DNA hybridization assay based on surface-activated microplates. Anal. Biochem. 225:252-257.

5.Cass, T. 1998. OLIGO 6. Biotechnology Software \& Internet Journal, Mary Ann Liebert, Inc., Larchmont, NY 5:22-23.

6.Chevrier, D., S. Rasmussen and J.-L. Guesdon. 1993. PCR product quantification by non-radioactive hybridization procedures us- ing an oligonucleotide covalently bound to microwells. Mol. Cell. Probes 7:187-197.

7.Cloney, L., C. Marlowe, A. Wong, R. Chow and R. Bryan. 1999. Rapid detection of mecA in methicillin resistant staphylococcus aureus using cycling probe technology. Mol. Cell. Probes 13:191-197.

8.De Beenhouwer, H., Z. Liang, P. de Rijk, C. van Eekeren and F. Portaels. 1995. Detection and identification of mycobacteria by DNA amplification and oligonucleotide-specific capture plate hybridization. J. Clin. Microbiol. 33:2994-2998.

9.Duck, P., G. Alvarado-Urbina, B. Burdick and B. Collier. 1990. Probe amplifier system based on chimeric cycling oligonucleotides. BioTechniques 9:142-147.

10.Jaeger, J.A., D.H. Turner and M. Zuker. 1989. Improved predictions of secondary structures for RNA. Proc. Natl. Acad. Sci. USA 86:7706-7710.

11.Kanaya, S. and M. Itaya. 1992. Expression, purification and characterization of a recombinant ribonuclease $\mathrm{H}$ from Thermus thermophilus HB8. J. Biol. Chem. 267:1018410192.

12.Modrusan, Z., F. Bekkaoui and P. Duck. 1998. Spermine-mediated improvement of cycling probe reaction. Mol. Cell. Probes 12:107-116.

13.Modrusan, Z., C. Marlowe, D. Wheeler, M. Pirseyedi and R. Bryan. 1999. Detection of vancomycin resistant genes vanA and vanB by cycling probe technology. Mol. Cell. Probes 13:223-231.

14.Nielsen, D.A., A. Novoradosky and D. Goldman. 1995. SSCP primer design based on single-strand DNA structure predicted by DNA folding program. Nucleic Acids Res. 23:22872291.

15.Rasmussen, S.R., M.R. Larsen and S.E. Rasmussen. 1991. Covalent immobilization of DNA onto polystyrene microwells: The molecules are only bound at the 5 ' end. Anal. Biochem. 198:138-142.

16.Tenover, F. 1988. Diagnostic deoxyribonucleic acid probes for infectious diseases. Clin. Microbiol. Rev. 1:82-101.

17.Thierry, D., P. Chavarot, G. Marchal, K. Le Thi, M. Ho, N. Nguyen, N. Le, S. Ledru et al. 1995. Mycobacterium tuberculosis strains unidentified using the IS6110 probe can be detected by oligonucleotides derived from the Mt308 sequence. Res. Microbiol. 146:325328.

18.Thierry, D., C. Chureau, C. Aznar and J-L. Guesdon. 1992. The detection of Mycobacterium tuberculosis in uncultured clinical specimens using the polymerase chain reaction and a non-radioactive DNA probe. Mol. Cell. Probes 6:181-191.

19.Wang, S. and L. Tay. 1999. Evaluation of three nucleic acid amplification methods for direct detection of Mycobacterium tuberculosis complex in respiratory specimens. J. Clin. Microbiol. 37:1932-1934.

20.Wolcott, M.J. 1992. Advances in nucleic acid-based detection methods. Clin. Microbiol. Rev. 5:370-386

21.Zammatteo, N., I. Alexandre, I. Ernest, L. Le, F. Brancart and J. Remacle. 1997. Comparison between microwell and bead supports 
for the detection of human cytomegalovirus amplicons by sandwich hybridization. Anal. Biochem. 253:180-189.

22.Zammatteo, N., C. Girardeaux, D. Delforge, J.-J. Pireaux and J. Remacle. 1996. Amination of polystyrene microwells: Application to the covalent grafting of DNA probes for hybridization assays. Anal. Biochem. 236:85-94.

22.Beach, R.C. 1981. The unified graphics system for Fortran 77 programs manual. Stanford, CA.

The authors would like to thank ID Biomedical (Bothell, WA, USA) for the material support. They also would like to thank I. Ernest for critical revision of the manuscript. Address correspondence to Stéphanie Warnon, Facultés Universitaires Notre-Dame de la Paix, Laboratoire de Biochimie cellulaire, 61 rue de Bruxelles 5000 Namur, Belgium. Internet: stephanie. warnon@fundp.ac.be

Received 10 November 1999; accepted 22 February 2000.

S. Warnon, N. Zammatteo, I. Alexandre, C. Hans and J. Remacle

Facultés Universitaires Notre-Dame de la Paix Namur, Belgium

\section{Application of DNA Topoisomerase-Activated Adapters to Riboprobe Synthesis}

BioTechniques 28:1160-1165 (June 2000)

\section{ABSTRACT}

Topoisomerase-activated adapters for rapid incorporation of the $T 7$ promoter into PCR products were made by hybridizing synthetic oligonucleotides and activating vaccinia DNA topoisomerase I. The adapters were used to incorporate the T7 promoter sequence into PCR products amplified from cDNA and genomic DNA. Mod- ified PCR products were used as templates to synthesize digoxigenin-labeled sense and cRNA probes by in vitro transcription with phage T7 RNA polymerase. The red/green cones were labeled by the antisense probe, but no specific signal was produced by the sense probe. These results demonstrate that topoisomerase-activated adapters provide a powerful and convenient tool for the rapid modification of PCR products.

\section{INTRODUCTION}

Recent advances in gene discovery technology and the human genome project have revealed thousands of new sequences, which are being characterized for tissue- or disease-specific expression. These analyses involve Northern blotting, RNase protection and in situ hybridization techniques that often rely on the use of riboprobes generated from DNA templates by in vitro transcription (IVT). Traditional approaches to template preparation for IVT include subcloning the DNA of interest into a plasmid vector with an appropriate RNA polymerase promoter (6) or incorporating the promoter sequences during PCR amplification with primers carrying the promoter sequence at their 5' ends (5).

While both techniques seem to be reliable and have certain advantages, the first one requires lengthy and laborious steps to transform bacterial cells and identify the right recombinant clones, plasmid DNA purification and linearization. The second one requires a synthesis of primers with 5'-end extensions containing RNA polymerase promoters for every DNA of interest, in addition to regular gene-specific primers, a method that may be time and cost inefficient over the long run.

This report introduces a novel technique to quickly generate templates for IVT from PCR products. The method is based on the use of topoisomerase-activated adapters containing the promoter for T7 RNA polymerase. The adapters are hybridized oligonucleotides that have been cleaved and activated by vaccinia DNA topoisomerase I. This enzyme has unique properties that allow cleavage of dsDNA at a CCCTT recognition site, form a covalent bond with the substrate and religate it to an acceptor DNA through a 5'-hydroxyl group 